\title{
MANAJEMEN KERELASIAN PELANGGAN DALAM MENCIPTAKAN KEPERCAYAAN PELANGGAN PADA COMMERCIAL BANKING CENTER BANDUNG PT. BANK MANDIRI (PERSERO) TBK
}

\author{
Renata Anisa* \\ Program Studi Hubungan Masyarakat, Fakultas Ilmu Komunikasi, Universitas Padjadjaran
}

\begin{abstract}
ABSTRAK
Perkembangan industri perbankan yang pesat membutuhkan konsep pemasaran yang baik dan tepat sasaran agar dapat menjadi pemain utama dalam industri perbankan. Manajemen kerelasian pelanggan atau lebih dikenal dengan Customer Relationship Management (CRM) merupakan salah satu strategi untuk menciptakan kepercayaan pelanggan. PT. Bank Mandiri (Persero) Tbk dinilai telah melaksanakan strategi CRM dengan baik. Namun masalah yang timbul adalah penurunan jumlah nasabah dana tiga tahun terakhir yang cukup signifikan pada Commercial Banking Center Bandung. Hal ini diduga disebabkan oleh CRM yang belum dilaksanakan dengan optimal, sehingga mempengaruhi kepercayaan pelanggan terhadap PT. Bank Mandiri (Persero) Tbk. Penelitian ini dimaksudkan untuk mengetahui bagaimana Customer Relationship Management dalam menciptakan kepercayaan pelanggan pada PT. Bank Mandiri (Persero) Tbk. Data yang diperoleh dalam penelitian ini didapatkan dari wawancara dan penyebaran kuesioner yang terdiri dari 22 pertanyaan. Kuesioner ini diberikan kepada 266 nasabah PT. Bank Mandiri (Persero) Tbk. Teknik pengambilan sampel yang digunakan adalah Stratified random sampling. Alat analisis yang digunakan untuk menguji hipotesa adalah analisis jalur (path analysis). Hasil pengujian hipotesa deskriptif menunjukkan bahwa Customer Relationship Management yang telah dilaksanakan Commercial Banking Center Bandung, PT. Bank Mandiri (Persero) Tbk cukup baik, namun belum memenuhi harapan pelanggan. Sedangkan Hasil pengujian hipotesa verifikatif menunjukkan bahwa CRM yang telah dilaksanakan Commercial Banking Center Bandung PT. Bank Mandiri (Persero) Tbk baik secara simultan maupun parsial menciptakan kepercayaan pelanggan. Besarnya pengaruh CRM dalam menciptakan kepercayaan pelanggan adalah sebesar $52,1 \%$ sedangkan $47,9 \%$ dipengaruhi faktor lain diluar penelitian ini.
\end{abstract}

Kata-kata kunci: Manajemen, relasi, pelanggan, kepercayaan pelanggan, bank

\section{CUSTOMER RELATIONSHIP MANAGEMENT IN CREATING CUSTOMER TRUST AT COMMERCIAL BANKING CENTER BANDUNG PT. BANK MANDIRI}

\begin{abstract}
The rapid development of the banking industry needs a good marketing concept and behavioural target oriented to become a leader in the banking industry. Customer Relationship Management (CRM) is a strategy to create customer trust. PT Bank Mandiri (Persero) Tbk has implemented the proper CRM strategies. But the problem lies in the decrease of customer for the last three years at Commercial Banking Center in Bandung. This is believed to be caused by a CRM that has not been implemented optimally, thus affecting the trust of customers towards PT Bank Mandiri (Persero) Tbk. This study is intended to determine how the CRM components create customer trust at PT Bank Mandiri (Persero) Tbk. The obtained data in this study are from interviews and questionnaires consisted of 22 questions. That data is distributed among 266 customers at PT Bank Mandiri (Persero) Tbk. The sampling technique used is stratified random sampling. Analysis tool that is used to test the hypothesis is path analysis. The test results of descriptive hypotheses show that Customer Relationship Management has been implemented at Commercial Banking Center Bandung, PT Bank Mandiri (Persero) Tbk, is showing good result, but does not meet customer expectations. At the same time, the result of verification hypothesis shows that CRM has been implemented at Commercial Banking Center Bandung, PT. Bank Mandiri (Persero) Tbk creates customer trust both partially and simultaneously. CRM gives contribution towards customer trust equal to 52,1\% while 47,9\% were influenced by the other factors outside this research.
\end{abstract}

Keywords: Management, customer, relationship, customer trust, bank

\footnotetext{
${ }^{\star}$ Korespondensi: Renata Anisa, S.Sos., M.M. Program Studi Hubungan Masyarakat, Fakultas Ilmu Komunikasi Universitas Padjadjaran, Jl. Raya Bandung-Sumedang Km.21.Email: renata.anisa@gmail.com
} 


\section{PENDAHULUAN}

Di tengah melemahnya ekonomi global yang masih berlanjut, perekonomian Indonesia pada tahun 2013 tumbuh cukup kuat, Bank Indonesia memperkirakan pertumbuhan ekonomi Indonesia sepanjang 2013 mencapai $5,7 \%$ lebih rendah dibandingkan pertumbuhan ekonomi 2012 sebesar 6,3\%. Perkembangan industri perbankan khususnya di dalam negeri mengalami pertumbuhan yang cukup pesat hal ini terlihat dari volume usaha, mobilitas dana masyarakat, maupun pemberian kredit. Industri perbankan pada tahun 2013 menguasai 90.46\% pangsa pasar sektor keuangan di Indonesia (Data biro riset majalah Infobank, 2013). Penguasaan pasar yang besar ini menyebabkan persaingan yang tinggi antara lembaga perbankan. Untuk itu diperlukan adanya konsep pemasaran yang baik dan tepat sasaran agar dapat menjadi pemain utama dalam industri perbankan.

Pada perkembangan perekonomian makro regional Jawa Barat di triwulan II2013 masih menunjukkan fase ekspansi yang ditandai dengan pertumbuhan yang lebih tinggi dibandingkan triwulan sebelumnya sebagaimana perkiraan sebelumnya. Realisasi PDRB ditriwulan II-2013 tercatatsebesar 6,1\%, meningkat dari triwulan sebelumnya sebesar 5,9\%. Peningkatan kinerja perekonomian Jawa Barat tersebut seiring dengan masih cukup baiknya prospek perekonomian domestik dan perekonomian global meskipun diwarnai ketidakpastian (uncertainty) dan risiko yang cukup tinggi (Data Bank Indonesia, 2013).

Seiring perkembangan perbankan Jawa Barat jumlah Bank di Jawa Barat khususnya Bandung mengalami pertumbuhan yang cukup pesat, menurut data Bank Indonesia jumlah Bank di Bandung mencapai sekitar 60 (enam puluh) bank yang terdiri dari Bank pemerintah dan swasta (Data Bank Indonesia, 2013).

PT. Bank Mandiri (Persero) Tbk merupakan salah satu bagian dari industri perbankan yang memiliki asset terbesar di Indonesia dengan total asset mencapai 672 Triliun pada tahun 2013. Dalam meningkatkan kinerja perusahaannya, dibentuklah beberapa direktorat yang memiliki spesialisasi untuk menjalankan usaha perbankan tertentu. Salah satu diantaranya adalah Direktorat Commercial
\& Business Banking. Direktorat ini memiliki fungsi sebagai penghimpun dana dan penyalur kredit bagi perusahaan dengan segmen komersial dengan limit 10-500 Milyar Rupiah. Direktorat Commercial \& Business Banking sendiri memiliki unit-unit kerja yang biasa disebut Bisnis Unit di 32 lokasi yang tersebar di seluruh Indonesia, untuk wilayah Jawa Barat terdapat satu Bisnis Unit Commercial Banking Center yaitu berada di Bandung (Data Bank Mandiri, 2013).

Semakin beragamnya pilihan yang ditawarkan dari banyak perusahaan telah membentuk kondisi masyarakat yang semakin kritis dalam memilih produk mana yang paling memberikan kepuasan bagi masyarakat. Dalam penentuan produk yang diinginkan, konsumen akan memperhatikan kualitas atas jasa yang ditawarkan. Konsumen akan melakukan keputusan pembelian apabila jasa yang ditawarkan memenuhi harapan mereka. Artinya pelanggan akan memutuskan untuk membeli atau membeli kembali apabila jasa yang diberikan sesuai dengan harapan konsumen.

PT. Bank Mandiri (Persero) Tbk menyadari pentingnya peran pelanggan dalam meningkatkan kinerja perusahaan. Perusahaan dituntut untuk menemukan dan membangun sistemmanajemen yangmampu secara potensial untuk meningkatkan dan mempertahankan para pelanggan yang bertujuan untuk mempertahankan kelangsungan hidup perusahaan.

Perhatian perusahaan terhadap Customer Relationship Management juga mulai semakin besar. Terciptanya kepuasan pelanggan dapat memberikan manfaat, diantaranya hubungan antara Bank Mandiri dan konsumen menjadi harmonis, sehingga menjadi dasar yang baik bagi keputusan pembelian.

Strategi yang perlu diperhatikan di tengah persaingan bisnis yang sangat ketat dewasa ini adalah Customer Relationship Management (CRM) yang merupakan salah satu sarana untuk menjalin hubungan yang berkelanjutan antara perusahaan dengan para stakeholder maupun shareholdernya. Saat ini banyak perusahaan yang memanfaatkan Customer Relationship Management (CRM) untuk menjalin hubungan dengan pelanggan. Dengan memanfaatkan Customer Relationship Management (CRM) yang terdiri dari komponen front office dan 
back office perusahaan akan mengetahui apa yang diharapkan dan dibutuhkan pelanggan. Menurut Pratama (2015) Frontliner sebagai mana artinya secara harfiah adalah 'garis depan', berartimerupakan petugasatau pegawai yang akan melakukan interaksi pertama ketika pelanggan mendatangi perusahaan. Sehingga, akan tercipta ikatan emosional yang mampu menciptakan hubungan bisnis yang erat dan terbuka serta komunikasi dua arah di antara mereka. Dengan demikian kesetiaan pelanggan dapat dipertahankan dan pelanggan tidak mudah berpindah.

Menurut Kotler and Amstrong (2008) CRM adalah konsep yang paling penting dalam pemasaran modern. Yang dalam arti lebih luas, CRM adalah keseluruhan proses membangun dan memelihara hubungan pelanggan yang menguntungkan dengan mengantarkan nilai dan kepuasan pelanggan yang unggul.

Hsin, Huery \& Cheng (2008) menyatakan bahwa apabila pelanggan puas terhadap barang atau pelayanan yang diterima, maka akan menimbulkan kesetiaan konsumen. Dengan kesetiaan konsumen terhadap produk atau layanan tersebut akan membuat konsumen kembali melakukan transaksi di masa datang.

Pada Tahun 2013, Bank Mandiri kembali meraih penghargaan Best Bank in Service Excellence 2013 di ajang Banking Services Exellence Award 2013, penghargaan ini adalah yang ke enam kalinya secara berturut-turut sejak tahun 2008. Penilaian dalam ajang ini dilakukan melalui survey Banking Service Excellence Monitor (BSEM) dengan metode mystery shopping di Jakarta, Bogor, Bekasi, Bandung, dan Solo. Evaluasi pelayanan bank dititikberatkan pada pengamatan proses service delivery dari tiap transaksi dan interaksi. Proses tersebut memberikan potret proses internal dan dukungan back office, teknologi tiap bank, serta sinergi antara sumber daya manusia, strategi bisnis dan proses bisnis dalam menciptakan pengalaman pelanggan (customer experience). Dan dari aspek penilaian yang meliputi customer service, teller, e-banking, phone banking officer, internet banking, satpam, ATM, mobile internet, peralatan banking hall, toilet dan beberapa aspek lain, Bank Mandiri memperoleh skor tertinggi yaitu 91,37 (Data Bank Mandiri, 2013).

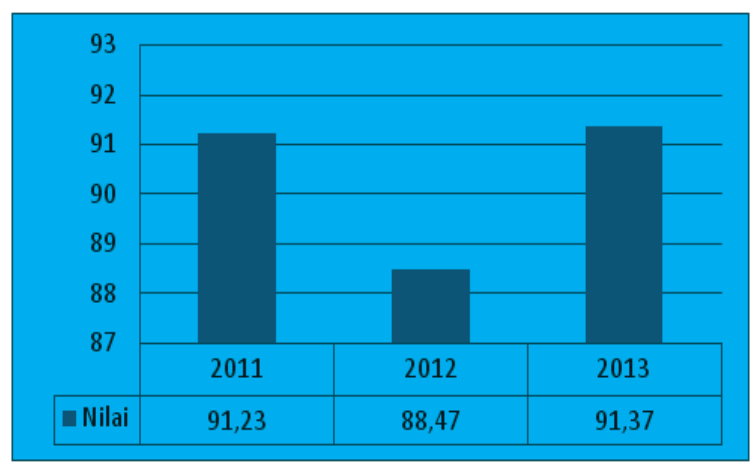

Gambar 1. Hasil Penilaian MRI Bank Mandiri

Sumber: Data Bank Mandiri 2013

Prestasi Bank Mandiri sebagai Best Bank in Service Excellent tidak sejalan dengan realitas pada unit bisnis Commercial Banking Center Bandung terjadi penurunan jumlah nasabah dana yang cukup signifikan pada tiga tahun terakhir yaitu tahun 2011, 2012, dan 2013, yang mengakibatnya penurunan portfolio dana di Commercial Banking Center Bandung. Hal ini mengindikasikan atas ketidakpuasan nasabah terhadap perusahaan (Data MRI Bank Mandiri, 2013).

Hubungan antara kepuasan dan loyalitas adalah dimana saat konsumen mencapai tingkat kepuasan tertinggi yang menimbulkan ikatan emosi yang kuat dan komitmen jangka panjang dengan merek perusahaan.

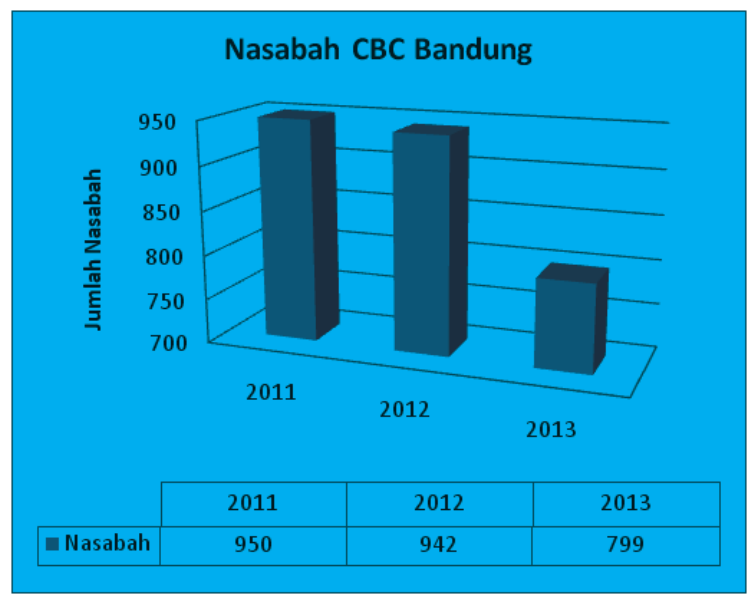

Gambar 2. Perkembangan Jumlah Nasabah Dana CBC Bandung

Sumber: Data Bank Mandiri 2013

Dari Gambar 2 terlihat adanya penurunan jumlah nasabah yang signifikan dari tahun 2011-2012. Bahkan pada tahun 2013 jumlah nasabahyang tidak lagimenggunakanjasa Bank Mandiri mencapai 143 nasabah. Penurunan jumlah nasabah ini diduga dikarenakan strategi CRM yang belum dilaksanakan dengan 
optimal, baik dari sisi produk yang ditawarkan belum dapat memenuhi keinginan dan kebutuhan konsumen, maupun sumber daya manusia yang berhubungan langsung dengan pelanggan, belum dapat memenuhi harapan konsumen. Sementara persaingan dalam industri perbankan semakin ketat, perusahaan dituntut untuk dapat memberikan kualitas produk dan jasa yang sesuai dengan harapan konsumen sehingga menciptakan kepercayaan pelanggan (Customer Trust).

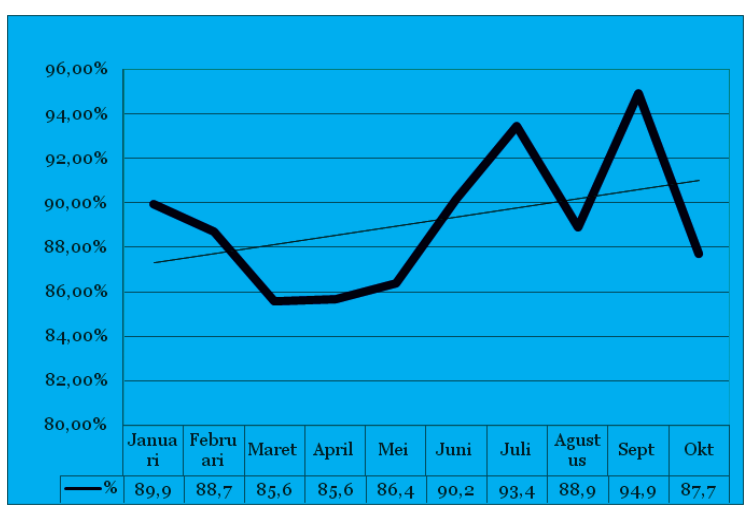

Gambar 3. Presentase Pencapaian Dana CBC Bandung 2013

Sumber: Data Bank Mandiri 2013

Dari Gambar 3 dapat terlihat pencapaian kinerja Dana CBC Bandung pada 2013 berada dibawah target yang telah ditetapkan perusahaan. Jumlah nasabah dari tahun 20112013 terus mengalami penurunan yang cukup signifikan sehingga berpengaruh terhadap pencapaian kinerja dana PT Bank Mandiri (Persero) Tbk. Pencapaian dana selama tahun 2013 tidak mencapai 100\%, sementara perusahaan membutuhkan likuiditas yang tinggi di tengah situasi ekonomi seperti saat ini dan pada akhirnya jika penurunan jumlah nasabah terus bertambah akan berdampak kepada kinerja PT. Bank Mandiri (Persero) Tbk secara nasional. Hal ini kemudian menjadi minat peneliti untuk menggali bagaimana manajemen kerelasian pelanggan dalam menciptakan kepercayaan pelanggan pada $\mathrm{CBC}$ Bandung PT Bank Mandiri (Persero) Tbk.

\section{METODE PENELITIAN}

Jenis dari penelitian ini adalah deskriptif dan verifikatif. Penelitian deskriptif ini bertujuan untuk memperoleh deskripsi mengenai pelaksanaan CRM yang telah dilakukan oleh Bank Mandiri serta kepercayaan pelanggan terhadap Bank Mandiri. Sementara penelitian verifikatif adalah untuk mengetahui bagaimana CRM yang telah dilakukan Bank Mandiri dalam menciptakan kepercayaan pelanggan. Data yang digunakan dalam penelitian ini berasal dari data primer dan data sekunder.

Dengan jenis penelitian deskriptif dan verifikatif ini maka dilakukan pengumpulan data dilapangan dengan menerapkan metode descriptive survey untuk melihat gambaran mengenai CRM serta kepercayaan pelanggan dan metode explanatory survey untuk menjelaskan hubungan antara variabelvariabel dalam CRM dengan kepercayaan pelanggan terhadap unit analisis yaitu nasabah Commercial Banking Center Bandung PT. Bank Mandiri (Persero) Tbk. Dengan metode descriptive survey dan explanatory survey peneliti dapat mengetahui gambaran CRM yang telah dilaksanakan PT. Bank Mandiri (Persero) Tbk, apakah telah sesuai dengan penilaian MRI sebagai Bank dengan pelayanan terbaik dan bagaimana CRM tersebut dalam menciptakan kepercayaan pelanggan.

Populasi dalam penelitian ini adalah Seluruh nasabah Commercial Banking Center Bandung PT. Bank Mandiri (Persero) Tbk sebanyak 799 nasabah. Metode Penarikan sampel yang digunakan dalam penelitian ini adalah stratified random sampling yaitu suatu metode pengambilan sampel dengan memilih secara acak sebagian dari populasi yang dijadikan sebagai responden, yang mempunyai peluang yang sama untuk terpilih sebagai sampel.

Dalam penelitian ini ukuran sampel yang diambil adalah 266 responden, ukuran sampel ini sudah cukup mewakili sampel, karena berdasarkan jumlah sample minimum yang diperlukan dalam penelitian ini adalah 266 responden. Pemilihan sampel selanjutnya dilakukan secara acak sederhana dari setiap strata dengan metode alokasi sebanding (proportional allocation methods).

Cara pengumpulan data yang dilakukan penulis adalah kuesioner, wawancara, dan studi kepustakaan. Pengumpulan data dengan menggunakan kuesioner dilakukan dengan cara memberikan sejumlah pertanyaan tertutup kepada responden untuk memperoleh data primer mengenai persepsi responden 
Tabel 1. Komposisi Nasabah CBC Bandung PT.Bank Mandiri (Persero) Tbk

\begin{tabular}{ccc}
\hline $\begin{array}{c}\text { Kategori } \\
\text { Nasabah }\end{array}$ & $\begin{array}{c}\text { Jumlah } \\
\text { Nasabah }\end{array}$ & Sampel \\
\hline$>50$ Milyar & 2 & 1 \\
$>$ 10 Milyar & 12 & 4 \\
$>$ 5 Milyar & 11 & 4 \\
$>$ 1 Milyar & 63 & 21 \\
$>$ 100 Juta & 87 & 29 \\
$>$ 25 Juta & 55 & 18 \\
$>$ 1 Juta & 569 & 189 \\
\hline Total & $\mathbf{7 9 9}$ & $\mathbf{2 6 6}$ \\
\hline
\end{tabular}

terhadap CRM di Commercial Banking Center Bandung PT. Bank Mandiri (Persero) Tbk. Kuesioner disusun berdasarkan item-item dan metode-metode yang digunakan yaitu Likert's Summanted Rating (LSR). Wawancara dilakukan dengan memberikan sejumlah pertanyaankepadastafdannasabah Commercial Banking Center Bandung PT. Bank Mandiri (Persero) Tbk untuk memperoleh tanggapan terhadap CRM yang telah dilaksanakan Bank Mandiri dalam menciptakan kepercayaan pelanggan. Studi kepustakaan dilakukan dengan menghimpun informasi yang relevan dengan variabel penelitian yang diperolah dari buku-buku ilmiah, laporan penelitian, jurnal, tesis, dan sumber-sumber tertulis lainnya. Metode analisis data yang digunakan dalam menguji hipotesis adalah teknik analisis jalur (path analysis).

\section{HASIL DAN PEMBAHASAN}

CRM yang dilakukan PT. Bank Mandiri (Persero) Tbk terhadap nasabah Commercial Banking Center Bandung cukup baik. Kemudian bila dilihat berdasarkan sub variabel, CRM yang dilakukan oleh bagian front office sudah baik, namun CRM yang dilakukan oleh bagian back office masuk dalam kategori cukup.

Hubungan antara komponen front office pada CRM $\left(\mathrm{X}_{1}\right)$ dengan komponen back office pada CRM $\left(\mathrm{X}_{2}\right)$ sebesar 0,393 dan masuk dalam kategori rendah atau lemah. Arah hubungan positif antara komponen front office dengan komponen back office pada CRM menujukkan bahwa komponen front office pada customer relationship management yang baik cenderung diikuti dengan perbaikan komponen back office dalam customer relationship management pada PT. Bank Mandiri (Persero) Tbk.

Kepercayaan nasabah Commercial Banking CenterBandung terhadap PT. Bank Mandiri (Persero) Tbk cukup tinggi. Secara bersama-sama kedua variabel independen (komponen front office dan komponen back office pada CRM) memberikan pengaruh sebesar 52,1\% (nilai $\mathrm{R}^{2}$ ) dalam menciptakan kepercayaan pelanggan pada PT. Bank Mandiri (Persero) Tbk. Sedangkan sisanya sebesar 47,9\% merupakan pengaruh faktor-faktor lain diluar kedua variabel independen.

Pengujian Hipotesis Secara Simultan. Hipotesis Statistik:

\begin{tabular}{|c|c|}
\hline $\begin{array}{l}\mathrm{H}_{0}: \text { Sen } \\
\rho \mathrm{YX}_{\mathrm{i}}= \\
=1 \& 2\end{array}$ & $\begin{array}{l}\text { Customerrelationshipmanagement } \\
\text { tidak menciptakan kepercayaan } \\
\text { pelanggan pada Commercial } \\
\text { Banking Center Bandung PT. Bank } \\
\text { Mandiri (Persero) Tbk. }\end{array}$ \\
\hline $\begin{array}{l}\mathrm{H}_{\mathrm{a}}: \text { Ada } \\
\rho \mathrm{YX}_{\mathrm{i}} \neq 0 \mathrm{i} \\
=1 \& 2\end{array}$ & $\begin{array}{l}\text { Customerrelationshipmanagement } \\
\text { menciptakan kepercayaan pelang- } \\
\text { gan pada Commercial Banking } \\
\text { Center Bandung PT. Bank Mandiri } \\
\text { (Persero) Tbk }\end{array}$ \\
\hline
\end{tabular}

Pengujian hipotesis tersebut dilakukan melalui statistik uji $\mathrm{F}$ dengan ketentuan tolak Ho jika $F_{\text {hitung }}$ lebih besar dari $F_{\text {tabel }}$, atau sebaliknya terima Ho jika $F_{\text {hitung }}$ lebih kecil atau sama dengan $F_{\text {tabel }}$. Melalui nilai koefisien determinasi (nilai $\mathrm{R}^{2}$ ) dapat dihitung nilai $\mathrm{F}$ dengan rumus sebagai berikut.

$$
\begin{aligned}
\mathrm{F}_{\text {hitung }} & =\frac{(\mathrm{n}-\mathrm{k}-1) \mathrm{R}_{\mathrm{Y}\left(\mathrm{X}_{1} \mathrm{X}_{2}\right)}^{2}}{\mathrm{k}\left(1-\mathrm{R}_{\mathrm{Y}\left(\mathrm{X}_{1} \mathrm{X}_{2}\right)}^{2}\right)} \\
\mathrm{F}_{\text {hitung }} & =\frac{(266-2-1) \times 0,521}{2 \times(1-0,521)} \\
& =143,03
\end{aligned}
$$

Dari tabel $\mathrm{F}$ untuk tingkat signifikansi 0.05 dan derajat bebas $(2 ; 263)$ diperoleh nilai $\mathrm{F}$ tabel sebesar 3,03. Karena dari hasil penelitian diperoleh nilai $F_{\text {hitung }}(143,03)$ dan lebih besar dibanding $\mathrm{F}_{\text {tabel }}(3,03)$, maka pada tingkat kekeliruan $5 \%$ diputuskan untuk menolak $\mathrm{H}_{0}$ sehingga $\mathrm{H}_{\mathrm{a}}$ diterima. 
Jadi berdasarkan hasil pengujian dapat disimpulkan bahwa Customer relationship management menciptakan kepercayaan pelanggan pada Commercial Banking Center Bandung PT. Bank Mandiri (Persero) Tbk.

PadaPengujianSecaraParsial,karenahasil dari pengujian secara simultan menyimpulkan terdapat pengaruh yang signifikan, selanjutnya dilakukan pengujian secara parsial untuk menguji apakah komponen front office pada customer relationship management menciptakan kepercayaan pelanggan dan juga menguji apakah komponen back office pada customer relationship management juga menciptakan kepercayaan pelanggan. Untuk menguji koefisien jalur masing-masing komponen customer relationship management digunakan statistik uji t yang dibandingkan dengan nilai t dari tabel pada tingkat kekeliruan $5 \%$ dan derajat bebas 263 pada pengujian dua arah yaitu sebesar 1,969 .

Komponen Front Office pada Customer Relationship Management menciptakan Kepercayaan Pelanggan. Hipotesis:

\begin{tabular}{|l|l|}
\hline $\mathrm{H}_{0}:$ & Komponen front office pada customer \\
$\rho \mathrm{YX}_{1}$ & $\begin{array}{l}\text { relationship management secara par- } \\
=0\end{array}$ \\
& $\begin{array}{l}\text { sial tidak menciptakan kepercayaan } \\
\text { pelanggan pada Commercial Banking } \\
\text { Center Bandung PT. Bank Mandiri } \\
\text { (Persero) Tbk. }\end{array}$ \\
\hline $\begin{array}{l}\mathrm{H}_{1}: \\
\rho \mathrm{YX}_{1} \\
\neq 0\end{array}$ & $\begin{array}{l}\text { Komponen front office pada customer } \\
\text { relationship management secara parsial } \\
\text { menciptakan kepercayaan pelanggan } \\
\text { pada Commercial Banking Center }\end{array}$ \\
& $\begin{array}{l}\text { Bandung PT. Bank Mandiri (Persero) } \\
\text { Tbk. }\end{array}$ \\
\hline
\end{tabular}

Tabel 2. Hasil Pengujian Komponen front office pada customer relationship management dalam menciptakan kepercayaan pelanggan

\begin{tabular}{ccccc}
\hline $\begin{array}{c}\text { Koef. } \\
\text { Jalur }\end{array}$ & $\mathbf{t}_{\text {-hitung }}$ & $\mathbf{t}_{\text {-tabel (db:263) }}$ & Ho & Ha \\
\hline 0,438 & 9,441 & 1,969 & ditolak & diterima \\
\hline
\end{tabular}

Berdasarkan hasil pengujian diatas dapat dilihat nilai $t_{\text {hitung }}$ variabel komponen front office pada customer relationship management $(9,441)$ lebih besar dari $t_{\text {tabel }}$ $(1,969)$. Karena nilai $t_{\text {hitung }}$ lebih besar dibanding $t_{\text {tabel}}$, maka dengan tingkat kekeliruan $5 \%$ diputuskan untuk menolak Ho sehingga Ha diterima. Jadi berdasarkan hasil pengujian dapat disimpulkan bahwa komponen front office pada customer relationship management menciptakan kepercayaan pelanggan pada Commercial Banking Center Bandung PT. Bank Mandiri (Persero) Tbk. Artinya dengan komponen front office dalam customer relationship management yang baik akan menciptakan kepercayaan pelanggan pada PT. Bank Mandiri (Persero) Tbk.

Jadi total pengaruh komponen front office pada customer relationship management dalam menciptakan kepercayaan pelanggan pada PT. Bank Mandiri (Persero) Tbk $=19,1 \%+7,4 \%$ $=\mathbf{2 6 , 5} \%$ dengan arah positif, artinya $26,5 \%$ perubahan yang terjadi pada kepercayaan pelanggan di PT. Bank Mandiri (Persero) Tbk dapat dijelaskan oleh komponen front office pada customer relationship management.

Komponen back office pada customer relationshipmanagement dalammenciptakan Kepercayaan pelanggan. Hipotesis:

\begin{tabular}{|c|c|}
\hline $\begin{array}{l}\mathrm{H}_{0}: \\
\rho \mathrm{YX}_{2} \\
=0\end{array}$ & $\begin{array}{l}\text { Komponen back office pada customer } \\
\text { relationship management secara } \\
\text { parsialtidakmenciptakankepercayaan } \\
\text { pelanggan pada Commercial Banking } \\
\text { Center Bandung PT. Bank Mandiri } \\
\text { (Persero) Tbk. }\end{array}$ \\
\hline $\begin{array}{l}\mathrm{H}_{1}: \\
\rho \mathrm{YX}_{2} \\
\neq 0\end{array}$ & $\begin{array}{l}\text { Komponen back office pada customer } \\
\text { relationship management secara } \\
\text { parsial menciptakan kepercayaan } \\
\text { pelanggan pada Commercial Banking } \\
\text { Center Bandung PT. Bank Mandiri } \\
\text { (Persero) Tbk. }\end{array}$ \\
\hline
\end{tabular}

Tabel 3. Hasil Pengujian Komponen back office pada customer relationship management dalam menciptakan kepercayaan pelanggan

\begin{tabular}{ccccc}
\hline $\begin{array}{c}\text { Koef. } \\
\text { Jalur }\end{array}$ & $\mathbf{t}_{\text {-hitung }}$ & $\mathbf{t}_{\text {-tabel (db:263) }}$ & Ho & Ha \\
\hline 0,427 & 9,206 & 1,969 & ditolak & diterima \\
\hline
\end{tabular}

Berdasarkan hasil pengujian diatas dapat dilihat nilai $\mathrm{t}_{\text {-hitung }}$ variabel komponen back office pada customer relationship management $(9,206)$ lebih besar dari $t_{\text {tabel }}(1,969)$. Karena nilai $t_{\text {hitung }}$ lebih besar dibanding $\mathrm{t}_{\text {tabel}}$, maka pada tingkat kekeliruan 5\% diputuskan untuk menolak Ho sehingga Ha diterima. Jadi berdasarkan hasil pengujian dapat disimpulkan bahwa komponen back office pada customer relationship management secara parsial menciptakan kepercayaan pelanggan pada 
Commercial Banking Center Bandung PT. Bank Mandiri (Persero) Tbk. Artinya dengan komponen back office dalam customer relationship management yang baik akan menciptakan kepercayaan nasabah pada PT. Bank Mandiri (Persero) Tbk.

Jaditotalpengaruhkomponenbackoffice pada customer relationship management dalam menciptakan kepercayaan pelanggan pada PT. Bank Mandiri (Persero) Tbk = $18,2 \%+7,4 \%=25,6 \%$ dengan arah positif, artinya $25,6 \%$ perubahan yang terjadi pada kepercayaan nasabah pada PT. Bank Mandiri (Persero) Tbk dapat dijelaskan oleh komponen back office pada customer relationship management.

\section{SIMPULAN}

Hasil kajian komponen front office pada CRM dalam menciptakan kepercayaan pelanggan pada Commercial Banking Center Bandung PT. Bank Mandiri (Persero) Tbk adalah baik. Aspek-aspek yang dinilai baik oleh sebagian besar nasabah adalah staf front office menghimpun data nasabah dengan lengkap mulai dari data utama seperti nama perusahaan, alamat, bidang usaha, dan pengurus perusahaan, data pendukung seperti omset perusahaan, tlp, fax, tujuan berhubungan dengan bank, jumlah pegawai, pengeluaran perusahaan hingga legalitas perusahaan. Sementara aspek-aspek yang dinilai kurang baik oleh sebagian nasabah adalah informasi mengenai produk, layanan, dan fasilitas perbankan belum disampaikan dengan jelas dan lengkap.

Berdasarkan hasil pengujian dapat disimpulkan bahwa komponen front office dalam CRM menciptakan kepercayaan pelanggan. Artinya komponen front office dalam CRM yang baik akan menciptakan kepercayaan pelanggan pada Commercial Banking Center Bandung PT. Bank Mandiri (Persero) Tbk.

Hasil kajian komponen back office pada CRM dalam menciptakan kepercayaan pelanggan pada Commercial Banking Center Bandung PT. Bank Mandiri (Persero) Tbk adalah cukup baik. Aspek-aspek yang dinilai baik oleh sebagian besar nasabah adalah staf back office membantu perusahaan pada saat melakukan transaksi keuangan. Namun sebagian besar aspek back office dinilai cukup bahkan kurang baik. Aspek tersebut adalah staf back office belum mampu mengidentikasi kebutuhan transaksi nasabah dan merancang kustomisasi produk dan layanan sesuai dengan kebutuhan nasabah. Staf back office dinilai belum dapat menjalin komunikasi yang baik dengan nasabah dan belum memberikan informasi dan solusi transaksi yang sesuai dengan kebutuhan nasabah.

Berdasarkan hasil pengujian dapat disimpulkan bahwa komponen back office dalam CRM menciptakan kepercayaan pelanggan. Artinya dengan komponen back office dalam CRM yang baik akan menciptakan kepercayaan pelanggan pada Commercial Banking Center Bandung PT. Bank Mandiri (Persero) Tbk.

Hasil kajian CRM dalam menciptakan kepercayaan pelanggan pada Commercial Banking Center Bandung PT. Bank Mandiri (Persero) Tbk adalah cukup baik. Artinya CRM yang dilaksanakan PT. Bank Mandiri (Persero) Tbk dinilai cukup baik oleh nasabah. Kemudian bila dilihat berdasarkan sub variabel, CRM yang dilaksanakan oleh staf front office sudah baik, namun CRM yang dilaksanakan oleh staf back office masuk dalam kategori cukup baik.

Berdasarkan hasil pengujian CRM dalam menciptakan kepercayaan pelanggan pada Commercial Banking Center Bandung PT. Bank Mandiri (Persero) Tbk dapat disimpulkan bahwa CRM menciptakan kepercayaan pelanggan pada Commercial Banking Center Bandung PT. Bank Mandiri (Persero) Tbk. Sehingga dengan CRM yang dinilai cukup belum dapat menciptakan kepercayaan pelanggan pada perusahaan, hal ini terlihat dari jumlah nasabah yang terus mengalami pengurangan dari tahun 2011 sampai dengan tahun 2013.

Berikut saran yang dapat dijadikan bahan masukan guna meningkatkan kualitas CRM pada Commercial Banking Center Bandung PT. Bank Mandiri (Persero) Tbk: (1) Staf Front Office dan Back Office diberikan pengetahuan yang mendalam mengenai produk, layanan, dan fasilitas yang dibutuhkan oleh nasabah, sehingga 
nasabah mendapatkan informasi perbankan yang memadai dan seluruh kebutuhan nasabah dapat diakomodasi oleh Bank., (2) Dalam upaya menjalin hubungan yang baik dengan nasabah, staf back office dalam hal ini Relationship Manager disarankan untuk menjalin komunikasi secara kontinu dengan nasabah baik secara langsung (tatap muka) maupun melalui media komunikasi. Hal ini penting, mengingat potensi nasabah yang cukup besar belum teridentifikasi secara optimal. Komunikasi dengan nasabah dilakukan untuk menggali keinginan dan kebutuhan transaksi nasabah sehingga seluruh transaksi dapat dilakukan di Bank Mandiri, serta mengoptimalkan pengendapan dana nasabah di Bank Mandiri, (3) Relationship Manager atau account officer untuk segmen komersial dapat disebarkan di seluruh cabang Bank Mandiri, sehingga nasabah dapat dengan mudah mendapatkan informasi mengenai produk dana, dan (4) Kepercayaan nasabah terhadap Bank Mandiri sudah cukup baik, namun kualitas produk dan layanan perlu ditingkatkan, sehingga memiliki keunggulan dibandingkan produk dan layanan bank lain. Produk dan layanan yang dirancang dapat menyesuaikan kebutuhan nasabah dengan suku bunga yang kompetitif.

\section{DAFTAR PUSTAKA}

Bank Indonesia. (2013). Data kajian ekonomi bank indonesia. Jawa Barat: Bank Indonesia Bandung.

Bank Mandiri. 2013. Data transactional banking. Jawa Barat: Commercial Banking Center Bandung.

Kotler, P. \& Armstrong, G. (2008). Prinsipprinsip pemasaran. Edisi 12. Jilid 1. Jakarta: Erlangga.

Hsin, K. C., Huery, R. Y., \& Cheng, Y., C. (2008). The Mediating Effects of Internal Marketing on Transformational Leadership and Job Performance of Insurance Salespersons in Taiwan. The business review, Cambridge. Vol. 11 Num. 1 December 2008.

Pratama, M. I. (2015). Pengaruh Rebranding Terhadap Citra Bank Jambi Pada Nasabah. Jurnal kajian komunikasi (JKK).Vol. 3. No.2. Desember.

Sheth,J.N., Parvatiyar,N. \& Shainesh, G. (2001). Customer relationsip management, tools and application emerging concepts, tools, and applications. New Delhi: Tata McGraw-Hill Publishing Company Limited.

Zikmund, W. G., McLeod, R. J., \& Gillbert, F. W. (2003). Customer relationship management: integrating marketing strategy and information technology. New York: John Wiley \& Sons 